\title{
The Court Case of Cow v. Plant
}

\author{
Angela To ${ }^{1}$ \\ Writing across the University of Alberta, $2021^{2}$ \\ Volume 2, pp. 37-42 \\ Published December 2021 \\ Keywords: argumentative writing, animal rights, vegetarianism
}

\section{BAILIFF}

All rise. Department One of the Court is now in session. Judge Lait presiding. Please be seated.

\section{JUDGE LAIT}

Good morning, ladies and gentlemen. Calling the case of Cow v. Plant. Are both sides ready?

MR. MLEKO AND I

Ready, your Honour.

\section{JUDGE LAIT}

Ladies and gentlemen of the jury: we are here to decide whether plant-based milk or cow's milk is better in terms of nutrition, environmental impact, and digestibility for those with food intolerances. First, we shall be deciding which milk is more nutritious since many people drink milk for its vitamins and nutrients. Second, we will be evaluating which milk has a lower environmental impact because as global temperatures rise, we need to lessen our greenhouse emissions and environmental footprint. Finally, we will decide which milk is more digestible for those with milk allergies and lactose intolerance; this is due to the fact that more than 7 million Canadians are unable to digest milk (Canadian Digestive Health Foundation). The better milk will be coming home with me today.

MR. MLEKO

Ladies and gentlemen of the jury: before we start, I think you should all be reminded of something very important. From the time of birth to our early childhood years, humans - like all mammals - rely on milk. Milk is a nutrient-dense food that is

\section{${ }^{1}$ Correspondence: Angela To (ahto@ualberta.ca)}

${ }^{2}$ Writing across the University of Alberta (WAUA) publishes undergraduate student writing from Writing Studies courses at the University of Alberta. You can find WAUA online at writingacrossuofa.ca. 
packed with protein, vitamin B, vitamin D, calcium, riboflavin, phosphorus, macronutrients and micronutrients (Rizzoli 1256). Due to this, none of us can deny that milk and dairy products are an essential part of our diet during infancy. But after all, with the nutrients cow's milk provides us, it seems a bit unfair to be vilifying cow's milk, doesn't it?

I [THE AUTHOR]

Mr. Mleko, although you are correct in that cow's milk is very nutritious, the same can be said about plant-based milks. I've brought in two experts: Dr. Sethi and Mr. Ferreria, who specializes in plant-based food research to educate us a bit more on the nutritional value of plant-based milks.

\section{JUDGE LAIT}

Will Dr. Sethi and Mr. Ferreira please come to the stand?

MR. FERREIRA

"Dairy-alternative milks tend to have fewer calories, less fat, more water content [and] less protein" (n.p.).

\section{DR. SETHI}

"In order to use plant-based milk as a substitute to cow's milk, fortification with protein, essential vitamins, and minerals is generally performed" (3419).

\section{I [THE AUTHOR]}

So overall, enriched plant-based milks are nutritionally similar to cow's milk. If one is deciding between plant-based and cow's milk, the amount of calcium and vitamins in either shouldn't be the deciding factor, since these fortified milks have comparable amounts of calcium and vitamins. However, cow's milk is higher in calories and in excess of fats, which can lead to weight gain. Skim milk may have comparable calories to plant-based milks, but according to nutritionist Michael Joseph, skim milk loses vitamin D and A during the manufacturing process (n.p.). So, if you are watching your figure, I suggest taking home plant-based milk.

\section{JUDGE LAIT}

Thank you, Dr. Sethi and Mr. Ferreria, you may step down.

\section{MR. MLEKO}

Although plant-based milks may be better for one's waistline, we can't say the same about their water usage. It takes $371 \mathrm{~L}$ of water to produce $1 \mathrm{~L}$ of almond milk (Marinova and Bogueva). This may be less than what is needed to produce a litre of cow's milk, but it is the production location of this milk that is problematic. Unlike cow's milk, most almond milk is produced in California. This is ironic, because California is facing a water shortage, and there is not enough fresh water to meet the demand. Cow's milk, on the other hand, is not produced in areas of water scarcity. 
Unlike plant-based milks, Canada does not export or import a lot of dairy products, which minimizes greenhouse gasses emitted from transport.

I [THE AUTHOR]

Mr. Mleko, since we are discussing the environmental impact of milk, I think it would be appropriate to allow food-sustainability experts Dr. Marinova and Dr. Bogueva to come to the stand.

JUDGE LAIT

Will Dr. Marinova and Dr. Bogueva please come to the stand!

DR. MARINOVA AND DR. BOGUEVA

"Any plant-based milk, be it made from beans, nuts, or seeds, has a lighter impact, in comparison to dairy milk; this is particularly true when it comes to greenhouse gas emissions and the use of water and land. In the case of cow's milk, its [CO2 emissions] vary between 1.14 in Australia and New Zealand, to 2.50 in Africa. Compare this to the [CO2 emissions] of plant-based milks, which are 0.42 for almond and coconut milk, and 0.75 for soy milk....Water use is similarly higher for cow's milk: 628 litres of water for every litre of dairy, compared to 371 for almond."

I [THE AUTHOR]

Although the production of almond milk requires a lot of water, it emits fewer greenhouse gasses than the production of cow's milk. Furthermore, Mr. Mleko, not all plant-based milks require as much water as almond milk. In fact, soy and oat milk production requires even less water, energy, and land. This means all plant-based milks have a lower environmental impact and emit fewer emissions than cow's milk. Greenhouse emissions are significant because they increase global temperatures, which can lead to rising sea levels, more severe weather, and depletion of the ozone layer.

JUDGE LAIT

Thank you, Dr. Marinova and Dr. Bogueva. You may step down. Are the attorneys ready with their final arguments?

MR. MLEKO AND I

Yes, your Honour.

MR. MLEKO

Despite experiencing increased popularity these recent years, "plant-based alternatives still struggle to produce cheese, because they lack casein and whey protein, the key ingredients that give dairy its taste and structure" (Kurzgesagt 8:21 8:27). Although plant-based dairy substitutes have done a good job at becoming a viable milk alternative, they still have a long way to go when it comes to the production of other dairy products. However, those who are lactose intolerant can continue to enjoy dairy products such as cow's milk, through lactose-free milk. 
Unlike plant-based alternatives, which struggle to produce cheese, lactose-free milk can be used to produce this much-loved product. Furthermore, people may struggle with switching over to plant-based milk because they may find it less palatable than cow's milk.

\section{I [THE AUTHOR]}

Your Honour, in no way am I an expert in the food industry. But, please allow me to contribute to this discussion by allowing me to share a personal anecdote from my childhood. Back when I was young, like all children, milk was the basis of my diet. Many things had changed throughout my childhood, but my love for milk was not one of them. I drank at least two glasses of milk every day: one after breakfast, and one before bedtime; however, on my 13th birthday, I woke up to find that I lost something very close and dear to me. What had I lost, you ask? My ability to digest lactose. Every glass of milk that I consumed caused my stomach to ache, and I was sent hurtling to the washroom every five minutes. I found that I was no longer able to consume my beloved beverage. I thought that I would never be able to taste another drop of white, creamy heavenly goodness until the day I died. Fortunately, I stumbled upon my salvation in the refrigerated section at the grocery store. Your Honour, what I had stumbled upon was almond milk. I can now enjoy my creamy and nutritious beverage once again, without having to fear stomach aches and a burning bottom. Sadly, I am not the only one with a story like this. Every year, millions of people suffer from our tragic inability to digest lactose. In fact, worldwide, $65-70 \%$ of the adult population is lactose intolerant (Bayless et al. 21). In a society where cheese-topped foods and fancy coffee shops are the norm, the inability to digest lactose is a digestive barrier that contributes to feelings of social exclusion. Unable to enjoy the same foods that our peers can, many lactose-intolerant people - such as myself - are forced to choose between feeling left out or feeling ill. But with the introduction of plant-based milks, that is no longer the case. Those who suffer from lactose intolerance can now enjoy the same foods and social environment as freely as their peers. We can finally go to a coffee shop and order a latte that does not send us running to the washroom half an hour later.

\section{JUDGE LAIT}

Will the clerk please stand? Has the jury reached a unanimous verdict?

\section{CLERK}

The jury finds that the judge will take home soy milk, which is plant-based milk. The decision was made in consideration of soy milk's lower water usage, lower land usage, and lower greenhouse emissions. The jury also chooses soy milk because fortified soy milk is nutritionally similar to cow's milk. In addition, given the fact that 
the judge's husband is lactose intolerant, bringing home soy milk will allow them to enjoy milk and cookies before bedtime.

JUDGE LAIT

The jury is thanked and excused. Court is adjourned!

\section{Works Cited}

Bayless, Theodore M., Elizabeth Brown, and David M. Paige. "Lactase Non-Persistence and Lactose Intolerance." Current Gastroenterology Reports, vol. 19, no. 5, 2017, 23. doi: 10.1007/s11894-017-0558-9.

Canadian Digestive Health Foundation. "What Is Lactose Intolerance?" Canadian Digestive Health Foundation, 2021, https://cdhf.ca/digestive-disorders/lactose-intolerant/what-is-lactose-intolerance/. Accessed 9 April 2021.

Ferreira, Sanae. "Going Nuts about Milk? Here's What You Need to Know About Plant-Based Milk Alternatives." American Society for Nutrition, 2020, nutrition.org/going-nuts-about-milk-heres-what-you-need-to-know-about-plant-based-milk-alternat ives/. Accessed 28 March 2021.

Marinova, Dora, and Diana Bogueva. "Which 'Milk' Is Best for the Environment?" The Conversation, 13 Oct. 2020, https://theconversation.com/which-milk-is-best-for-the-environment-we-compared-dairy-nut-so y-hemp-and-grain-milks-147660. Accessed 28 March 2021.

Kurzgesagt - In a Nutshell. "Milk. White Poison or Healthy Drink?" YouTube, uploaded by Kurzgesagt, 26 Jan. 2020, https://youtu.be/oakWgLqCwUcl.

Rizzoli, Rene. "Dairy Products, Yogurts, and Bone Health." The American Journal of Clinical Nutrition, vol. 99, no. 5, May 2014, pp. 1256S-1262S. https://doi.org/10.3945/ajcn.113.073056.

Sethi, Swati, et al. "Plant-Based Milk Alternatives an Emerging Segment of Functional Beverages: a Review." Journal of Food Science and Technology, vol. 53, no. 9, 2016, pp. 3408-3423. doi: 10.1007/s13197-016-2328-3.

(c) (1) $(-$ This work is licensed under CC BY-NC-ND 4.o. To view a copy of this license, visit https://creativecommons.org/licenses/bv-nc-nd/4.0. 
To | The Court Case of Cow v. Plant | Writing across the University of Alberta

[This page has been left blank intentionally] 